\title{
A longitudinal comparison of metacognitive therapy and acceptance and commitment therapy models of anxiety disorders
}

\author{
Francisco J. Ruiz ${ }^{1, *}$, and Paula Odriozola-González² \\ ${ }^{1}$ Fundación Universitaria Konrad Lorenz (Colombia). \\ ${ }^{2}$ Universidad de Valladolid (Spain).
}

\begin{abstract}
Título: Una comparación longitudinal de los modelos de los trastornos de ansiedad de la terapia metacognitiva y la terapia de aceptación y compromiso.

Resumen: La terapia metacognitiva (MCT) sugiere que los trastornos de ansiedad son causados por el síndrome atencional cognitivo (CAS), que es apoyado por creencias metacognitivas disfuncionales. La terapia de aceptación y compromiso (ACT) enfatiza el rol de la fusión cognitiva y la evitación experiencial en el desarrollo de estos trastornos. En este estudio se hipotetizó que los conceptos de fusión cognitiva y evitación experiencial mediarían la relación entre las creencias metacognitivas disfuncionales y los síntomas de ansiedad/estrés. Se utilizó un diseño longitudinal. Ciento seis participantes respondieron en dos ocasiones a una encuesta online en el lapos de nueve meses. La fusión cognitiva en el Tiempo 2 medió el efecto de las creencias metacognitivas en el Tiempo 1 en los síntomas de ansiedad en el Tiempo 2, mientras que la fusión cognitiva y la evitación experiencia mediaron el efecto en los síntomas de estrés. La fusión cognitiva medió el efecto de las creencias metacognitivas positivas sólo en los síntomas de estrés. Los resultados justifican comparaciones adicionales de los modelos de MCT y ACT.
\end{abstract}

Palabras clave: evitación experiencial; fusión cognitiva; creencias metacognitivas; ansiedad; estrés.

\section{Introduction}

The Self-Regulatory Executive Function model (S-REF; Wells, 2000; Wells \& Matthews, 1994) suggests that the cause of anxiety disorders is the activation of a specific pattern of thinking called the cognitive attentional syndrome (CAS), which consists of repetitive thinking in the form of worry and rumination, excessive attentional focus on thoughts and feelings including threat monitoring, and counterproductive coping behaviors such as avoidance and thought suppression. The CAS is thought to be problematic because it extends negative thinking, leads to reduced attentional flexibility and failure to exercise appropriate control over negative experiences (Wells, 2009).

According to the S-REF model, the CAS is generated by two broadly defined types of metacognitive beliefs: (a) positive beliefs concerning the benefits of worrying, ruminating, threat monitoring, and maladaptive coping strategies; and (b) negative beliefs about the uncontrollability of worry and rumination, and the importance and dangerous consequences of anxiety experiences. On the one hand, positive beliefs support the use of the CAS as coping strategies in response to anxiety and stress, which in turn, due to the nature of the CAS, ironically causes more emotional disturbance. On the other hand, negative beliefs contribute to the persistence of

* Dirección para correspondencia [Correspondence address]:

Francisco J. Ruiz. Fundación Universitaria Konrad Lorenz, Carrera 9 bis, $\mathrm{N}^{\circ}$ 62-43, Bogotá (Colombia).

E-mail: franciscoj.ruizj@konradlorenz.edu.co
Abstract: Metacognitive therapy (MCT) suggests that anxiety disorders are caused by the cognitive attentional syndrome (CAS), which is supported by dysfunctional metacognitive beliefs. Acceptance and commitment therapy (ACT) emphasizes the role of cognitive fusion and experiential avoidance in the development of these disorders. In this study, it was hypothesized that the ACT concepts of cognitive fusion and experiential avoidance would mediate the relationship between dysfunctional metacognitive beliefs and anxiety/stress symptoms. A longitudinal design was employed. One hundred and six nonclinical participants responded twice to an online survey with a lapse of nine months. Cognitive fusion at Time 2 mediated the effect of negative metacognitive beliefs at Time 1 on anxiety symptoms at T2, whereas both cognitive fusion and experiential avoidance mediated the effect on stress symptoms. Cognitive fusion mediated the effect of positive metacognitive beliefs only on stress symptoms. These results warrant further comparison of the MCT and ACT models.

Key words: experiential avoidance; cognitive fusion; metacognitive beliefs; anxiety; stress. worry and rumination because the individual lacks metacognitive awareness that these processes are subject to voluntary control. Accordingly, individuals get entangled in worry and ruminative cycles that they are unable to stop and fail to realize that the CAS is the problem and not the solution to their situation. The CAS is also provoked and further promotes the dominance of the object mode of processing, which entails experiencing thoughts as reflecting reality and with no separation between the self and the act of thinking. Conversely, a more adaptive mode of processing is the metacognitive mode that involves experiencing thoughts as simply passing events in the mind.

In conclusion, the S-REF model proposes that positive and negative metacognitive beliefs lead to the use of CAS, which is the most proximal cause of the development and maintenance of anxiety disorders. In other words, the effect of dysfunctional metacognitive beliefs on anxiety is mediated by engagement in CAS.

Another relatively recent approach to anxiety disorders is acceptance and commitment therapy (ACT; Hayes, Strosahl, \& Wilson, 1999). The ACT model emphasizes the pernicious role of cognitive fusion and experiential avoidance in the development and maintenance of anxiety disorders. Cognitive fusion refers to a verbal process by which individuals become attached to private experiences (e.g., thoughts, memories, sensations, etc.) and fail to discriminate that they are only ongoing experiences that do not necessarily have to guide behavior. Therefore, when individuals are fused with their private experiences, they act according to their literal con- 
tent, which usually leads to engaging in experiential avoidance strategies (e.g., suppression, distraction, worry, rumination, etc.). Experiential avoidance is a pattern of verbal regulation based on deliberate efforts to either avoid or escape from discomfiting private experiences even when doing so leads to actions that are inconsistent with one's values and goals (Hayes, Wilson, Gifford, Follette, \& Strosahl, 1996). When rigidly applied, experiential avoidance has a paradoxical effect because, although it often works in the short term by reducing discomfort and increasing the feeling that one is doing what one is supposed to do, it usually expands unwanted private experiences in the long term and further prevents the person from moving toward valued directions.

As the MCT and ACT models come from different philosophical and theoretical standpoints, they have not been compared in detail in the literature. However, we suggest that MCT and ACT models share an important number of similarities. For instance, from the MCT perspective, the ACT processes of experiential avoidance and cognitive fusion can be seen as parts of the CAS. Indeed, worry and rumination have been proposed to be experiential avoidance strategies (Borkovec, 1994; Giorgio et al., 2010; Roemer \& Orsillo, 2002). Likewise, the object mode of processing and paying excessive attentional focus to thoughts and feelings resembles cognitive fusion. Also, like the CAS, experiential avoidance is thought to have counterproductive effects that lead to more emotional disturbance. From an ACT perspective, dysfunctional metacognitive beliefs can be interpreted as verbal rules that prompt cognitive fusion with anxious thoughts and feelings and the use of experiential avoidance strategies such as worry, rumination, thought suppression, etc. to deal with them.

One important difference between both models is that while in the S-REF model, metacognitive beliefs are seen as the cause of the CAS, in the ACT model, metacognitive beliefs can be seen as derivatives of engaging in cognitive fusion and experiential avoidance. In this sense, both cognitive fusion and experiential avoidance are relatively simple verbal processes, and individuals do not need to present dysfunctional metacognitive beliefs in order to engage in them. Conversely, as individuals engage in experiential avoidance, positive metacognitive beliefs will likely emerge as they can experience their often short-term positive consequences (i.e., reducing unpleasant private experiences). Likewise, negative metacognitive beliefs will likely appear as individuals further engage in cognitive fusion and experiential avoidance because they can begin to experience that anxiety is more present and causes negative consequences in their lives and that their own worry, rumination, and threat monitoring are uncontrollable (i.e., negative metacognitive beliefs), as they have become predominant behavioral repertoires. Once these positive and negative metacognitive beliefs are generated, they further promote cognitive fusion and experiential avoidance, which only aggravate the situation.

The current study was designed to preliminarily compare the MCT and ACT models of anxiety disorders. One hun- dred and six nonclinical participants responded twice to an online survey containing questionnaires assessing the constructs of interest with a lapse of nine months. Firstly, according to our interpretation of the CAS as involving cognitive fusion and experiential avoidance, and according to the S-REF model, we hypothesized that both ACT constructs would longitudinally mediate the effect of dysfunctional metacognitive beliefs in the development of anxiety and stress symptoms. Secondly, according to the ACT model, we hypothesized that experiential avoidance and cognitive fusion as measured at Time 1 (T1) would significantly predict dysfunctional metacognitive beliefs at Time 2 (T2) even when controlling for metacognitive beliefs and anxiety/stress symptoms at T1. Conversely, we did not expect that dysfunctional metacognitive beliefs at T1 would be significant predictors of experiential avoidance and cognitive fusion at T2 when controlling for both ACT processes at T1.

\section{Method}

\section{Participants}

The sample consisted of 289 participants (59.5\% females) with age ranging between 22 and 82 years $(M=35.38, S D=$ $8.63)$. The relative educational level of the participants was: $7.3 \%$ primary studies, $32.8 \%$ mid-level study graduates, and $59.9 \%$ were college graduates. They responded to an anonymous internet survey distributed through social media. All of them were Spanish speakers. Thirty-six percent reported having received psychological or psychiatric treatment at some time, but only $6.6 \%$ were currently in treatment. Also, $4.8 \%$ of participants reported consumption of some psychotropic medication.

\section{Instruments}

Acceptance and Action Questionnaire - II (AAQ-II; Bond et al., 2011; Spanish version by Ruiz, Langer, Luciano, Cangas, \& Beltrán, 2013; Ruiz et al., 2016). The AAQ-II is a general measure of experiential avoidance or psychological inflexibility. It consists of 7 items that are rated on a 7 -point Likerttype scale $(1=$ never true; $7=$ always true $)$. The items reflect unwillingness to experience unwanted emotions and thoughts and the inability to be in the present moment and behave according to value-directed actions when experiencing psychological events that could undermine them. The AAQ-II has shown a one-factor solution and good psychometric properties.

Believability of Anxious Feelings and Thoughts Questionnaire (BAFT; Herzberg et al., 2012; Spanish version by Ruiz, Odriozola-González, \& Suárez-Falcón, 2014). The BAFT is a self-report measure of cognitive fusion with anxious thoughts and feelings. It consists of 16 items representing different thoughts which are rated on a 7-point Likert-type scale ranging from 1 (not at all believable) to 7 (completely believable) to the extent that the individual believes in them. The 
Spanish version of the BAFT showed a hierarchical factor structure with two lower order factors that were labeled Negative Evaluation (12 items) and Emotion Regulation (4 items) and a second-order factor. The emotion regulation factor showed significantly lower correlations with experiential avoidance and anxiety-related measures, and the use of the 12 items of the negative evaluation factor was suggested as a reduced version of the BAFT. Accordingly, this reduced version of the BAFT was used in this study. The BAFT has excellent internal consistency and good psychometric properties.

Metacognitions Questionnaire-30 (MCQ-30; Wells \& Cartwright-Hatton, 2004). The MCQ-30 is a short version of the MCQ-65. It is a 30-item, 4-point Likert-type scale $(1=$ do not agree; 4 agree very much) that contains the following five factors: Positive Beliefs about Worry, Negative Beliefs about Uncontrollability and Danger of Worry, Beliefs about the Need to Control Thoughts, Cognitive Confidence, and Cognitive Self-Consciousness. Only the first three factors were administered in this study. The MCQ-30 has shown good internal consistency, convergent validity, and acceptable testretest reliability. We used the Spanish version employed by Odriozola-González (2011), which showed good internal consistency in the subscales administered in the current study (alphas from .78 to .84).

Depression Anxiety and Stress Scales-21 (DASS-21; Antony, Bieling, Cox, Enns, \& Swinson, 1998; Spanish version by Daza, Novy, Stanley, \& Averill, 2002). The DASS-21 is a 21 item, 4-point Likert-type scale $(0=$ did not apply to me at all; 3 = applied to me very much, or most of the time) consisting of sentences describing negative emotional states. It contains three subscales (Depression, Anxiety, and Stress), each one with seven items, and has shown good internal consistency and convergent and discriminant validity. Only the results of the Anxiety and Stress subscales will be presented here because they are the criterion variable of this study.

\section{Procedure}

At Time 1 (T1), an anonymous survey was distributed through social media with the title "Survey of Psychological Discomfort Applied to Online General Population." The first page of the survey stated that the data obtained would only be used for scientific purposes and specified the requirements to participate: (a) to be older than 18 years old, and (b) to be a Spanish speaker. When participants provided informed consent, the previous questionnaires appeared in the order presented above. Nine months after the first survey application (T2), participants were invited to respond to the follow-up survey, which contained the same questionnaires, and was completed by 106 participants. Participants' responses at T1 and T2 were matched according to sociodemographic information (e.g., birth date, sex, education level, etc.).

\section{Data Analysis}

All statistical analyses were run in SPSS $22^{\circ}$. Descriptive data, Cronbach's alphas, and zero-order relationships between all constructs were computed first. Because scores on the constructs of interest did not show a normal distribution, Mann Whitney's $U$ was computed to analyze potential differences between participants who completed the study and those who did not respond at T2.

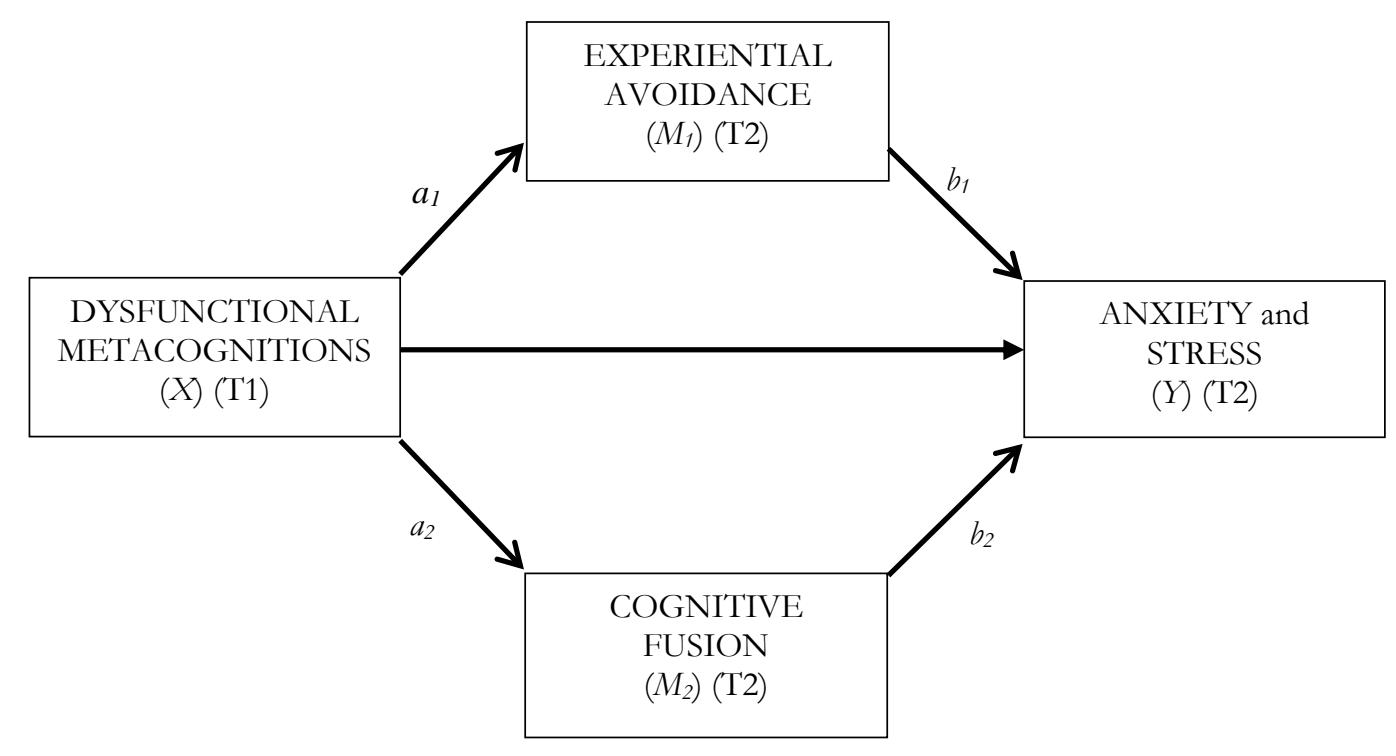

Figure 1. Mediation Model Tested: Experiential Avoidance and Cognitive Fusion as Mediators of the Effect of Anxiety Sensitivity on Emotional Symptoms. 
Subsequently, several regression analyses were conducted. To explore potential multicollinearity problems, the variance inflation factor (VIF) for each regression analysis was computed first. Following Ato and Vallejo (2007), VIF values above 10 were considered as indicative of problematic multicollinearity. None multicollinearity problem was found. Six independent, parallel, multiple mediation analyses (Ato \& Vallejo, 2011) were conducted with the non-parametric bootstrapping procedure to estimate direct and indirect effects using the PROCESS package (Hayes, 2013). In all mediation analyses, scores on one type of metacognitive beliefs (positive, negative, or need to control thoughts beliefs) $(X)$ as measured at T1 served as predictor variable. Experiential avoidance $\left(M_{1}\right)$ and cognitive fusion $\left(M_{2}\right)$ scores as measured at T2 were entered as putative mediators. Although the AAQ-II and BAFT were administered at both waves, scores on T2 were selected because they were the most accurate assessment of what occurred between T1 and T2. Specific emotional symptomatology at T2 served as criterion variables (Y): anxiety or stress. Lastly, to control for T1 symptom level, scores in the same type of symptom entered as $Y$ were included as covariates. As shown in Figure 1, the effect of metacognitive beliefs $(\mathrm{X})$ on anxiety and stress symptoms $(\mathrm{Y})$ is modeled through three pathways: one direct and two indirect pathways. The direct effect (c) runs from metacognitive beliefs to anxiety or stress symptoms without passing through either experiential avoidance or cognitive fusion. The first indirect pathway runs from metacognitive beliefs to anxiety or stress symptoms through experiential avoidance $\left(a_{1} b_{1}\right)$. The second indirect pathway (IE2) runs from metacognitive beliefs to symptoms through cognitive fusion $\left(a_{2} b_{2}\right)$. The effect sizes of mediation were computed using the completely standardized indirect effect $\left(a b_{c s}\right.$; Preacher \& Kelley, 2011). This effect size measure relies on the product of betas for paths $a$ and $b$, and can be interpreted as the expected change in the dependent variable (i.e., emotional symptoms) per unit change in the predicting variables (i.e., metacognitive beliefs) that occurs indirectly through the mediators (i.e., experiential avoidance and cognitive fusion). Following Kenny's (2014) suggestion, small, medium, and large effect sizes would be, respectively, .01, .09, and .25.

Lastly, to examine the predictors at T1 of dysfunctional metacognitive beliefs at $\mathrm{T} 2$, three hierarchical regression analyses were conducted. Step 1 entered all three metacognitive beliefs. Step 2 entered anxiety and stress symptoms. Lastly, experiential avoidance and cognitive fusion were introduced in Step 3. To explore the predictors at T1 of experiential avoidance and cognitive fusion at T2, two additional hierarchical regression analyses were conducted. Step 1 entered experiential avoidance and cognitive fusion; Step 2 entered anxiety and stress symptoms; and Step 3 entered all three dysfunctional metacognitive beliefs.

\section{Results}

\section{Descriptive Data, Internal Consistencies and Zero- Order Correlations}

Table 1 shows the descriptive data, internal consistencies obtained for each scale, and the correlations between measures at T1 and T2 for the 106 participants who completed the study. The internal consistencies of the AAQ-II, BAFT, and the Anxiety and Stress subscales of the DASS-21 were good. With respect to the factors of the MCQ-30, internal consistencies were acceptable, ranging from .73 to .87 . In all cases, Cronbach's alphas were similar to previous evidence using all these instruments. Participants who completed the study did not show statistically significant differences from the participants who did not respond to the questionnaires at T2 in any measure.

Table 1. Descriptive Data, Internal Consistencies, and Correlations at T1 and T2.

\begin{tabular}{|c|c|c|c|c|c|c|c|c|c|c|c|c|c|c|c|c|}
\hline & 1 & 2 & 3 & 4 & 5 & 6 & 7 & 8 & 9 & 10 & 11 & 12 & 13 & $M$ & $S D$ & $a$ \\
\hline 1. Anxiety (T1) & & & & & & & & & & & & & & 2.53 & 2.94 & .83 \\
\hline 2. Stress (T1) & $.66^{* *}$ & & & & & & & & & & & & & 5.60 & 3.69 & .82 \\
\hline 3. Experiential avoidance (T1) & $.41^{* *}$ & $.48^{* *}$ & & & & & & & & & & & & 19.56 & 7.54 & .89 \\
\hline 4. Cognitive fusion (T1) & $.59^{* *}$ & $.64^{* *}$ & $.72^{* *}$ & & & & & & & & & & & 29.60 & 14.07 & .91 \\
\hline 5. Positive meta-beliefs (T1) & $.21^{*}$ & .12 & .19 & .18 & & & & & & & & & & 9.20 & 3.25 & .87 \\
\hline 6. Negative meta-beliefs (T1) & $.33^{* *}$ & $.45^{* *}$ & $.60^{* *}$ & $.57^{* *}$ & $.26^{* *}$ & & & & & & & & & 12.19 & 3.17 & .76 \\
\hline 7. Beliefs need to control (T1) & $.30^{* *}$ & $.35^{* *}$ & $.46^{* *}$ & $.58^{* *}$ & $.22^{*}$ & $.48^{* *}$ & & & & & & & & 11.17 & 3.26 & .75 \\
\hline 8. Anxiety (T2) & $.53^{* *}$ & $.37^{* *}$ & $.39^{* *}$ & $.45^{* *}$ & .09 & $.30^{* *}$ & $.24^{*}$ & & & & & & & 2.16 & 2.67 & .84 \\
\hline 9. Stress (T2) & $.35^{* *}$ & $.44^{* *}$ & $.43^{* *}$ & $.39^{* *}$ & .11 & $.37^{* *}$ & $.20^{*}$ & $.71^{* *}$ & & & & & & 4.84 & 3.68 & .87 \\
\hline 10. Experiential avoidance (T2) & $.27^{* *}$ & $.34^{* *}$ & $.79^{* *}$ & $.60^{* *}$ & $.20^{*}$ & $.43^{* *}$ & $.36^{* *}$ & $.36^{* *}$ & $.49^{* *}$ & & & & & 18.00 & 7.31 & .89 \\
\hline 11. Cognitive fusion (T2) & $.45^{* *}$ & $.39^{* *}$ & $.58^{* *}$ & $.63^{* *}$ & $.26^{* *}$ & $.42^{* *}$ & $.42^{* *}$ & $.56^{* *}$ & $.55^{* *}$ & $.61^{* *}$ & & & & 27.24 & 13.85 & .92 \\
\hline 12. Positive meta-beliefs (T2) & .11 & .04 & $.20^{*}$ & .12 & $.66^{* *}$ & $.21^{*}$ & $.21^{*}$ & .09 & .17 & $.25^{*}$ & $.38^{* *}$ & & & 8.90 & 2.99 & .87 \\
\hline 13. Negative meta-beliefs (T2) & $.30^{* *}$ & $.44^{* *}$ & $.62^{* *}$ & $.60^{* *}$ & .17 & $.68^{* *}$ & $.46^{* *}$ & $.33^{* *}$ & $.49^{* *}$ & $.63^{* *}$ & $.53^{* *}$ & $.29^{* *}$ & & 11.47 & 3.26 & .76 \\
\hline 14. Beliefs need to control (T2) & $.29^{* *}$ & $.45^{* *}$ & $.60^{* *}$ & $.65^{* *}$ & $.25^{* *}$ & $.60^{* *}$ & $.66^{* *}$ & $.28^{* *}$ & $.27^{* *}$ & $.55^{* *}$ & $.52^{* *}$ & $.37^{* *}$ & $.64^{* *}$ & 10.20 & 3.15 & .75 \\
\hline
\end{tabular}


Mediation Analyses of the Effect of Positive Metacognitive Beliefs on Anxiety and Stress

Table 2 presents the set of regression analyses conducted to explore the mediating role of experiential avoidance and cognitive fusion in the relationship between positive metacognitive beliefs and anxiety (upper part of the table) and stress symptoms (lower part). In the first two models, when controlling for anxiety levels at T1, positive metacognitive beliefs $(X)$ at T1 did not significantly predict experiential avoidance at T2 $\left(M_{1}\right)(T E=.322, S E=.216, p=.139)$ and marginally predicted cognitive fusion at T2 $\left(M_{2}\right)(T E=.737$, $S E=.377, p=.053)$. Only anxiety symptoms at $\mathrm{T} 1(\mathrm{TE}=$ $.322, S E=.078, p<.001)$ and cognitive fusion at T2 $(\mathrm{TE}=$ $.078, S E=.020, p<.001)$ were significant predictors of anxiety symptoms at T2. The model accounted for $41.7 \%$ of the variance. The total indirect effect of positive metacognitive beliefs on anxiety through experiential avoidance and cognitive fusion was not significant $(\mathrm{TE}=.061,95 \%$ BC CI [-
$.006, .139]$; although it was significant at $90 \%$ BC CI [.007, $129])$, with a small effect size $\left(a b_{c s}=.086\right)$.

With regard to stress symptoms, positive metacognitive beliefs at T1 marginally predicted experiential avoidance $\left(M_{1}\right)$ $(T E=.354, S E=.207, p=.089)$ and significantly predicted cognitive fusion at T2 $\left(M_{2}\right)(T E=.937, S E=.378, p=.015)$. Stress symptoms at $\mathrm{T} 1(\mathrm{TE}=.243, \mathrm{SE}=.085, p=.005)$, cognitive fusion (TE $=.090, S E=.027, p=.001)$ and experiential avoidance at $\mathrm{T} 2(\mathrm{TE}=.104, S E=.050, p=.040)$ significantly predicted stress symptoms at T2. The model accounted for $39 \%$ of the variance. The total indirect effect of positive metacognitive beliefs at $\mathrm{T} 1$ on stress symptoms at T2 was statistically significant $(T E=.121,95 \%$ BC CI [.040, $.252])$ and with a medium effect size $\left(a b_{c s}=.118\right)$. The specific indirect effects through experiential avoidance $(T E=.037$, $95 \%$ BC CI $\left.[.001, .114], a b_{c s}=.036\right)$ and cognitive fusion (TE $=.084,95 \%$ BC CI $\left.[.024, .212], a b_{c s}=.082\right)$ were also significant.

Table 2. Results from the Regression Analyses Examining the Parallel Multiple Mediator Model of the Effect of Positive Metacognitive Beliefs (X) on Anxiety (First Part of the Table) and Stress (Second Part of the Table) (Y) through Experiential Avoidance $\left(\mathrm{M}_{1}\right)$ and Cognitive Fusion ( $\left.\mathrm{M}_{2}\right)$.

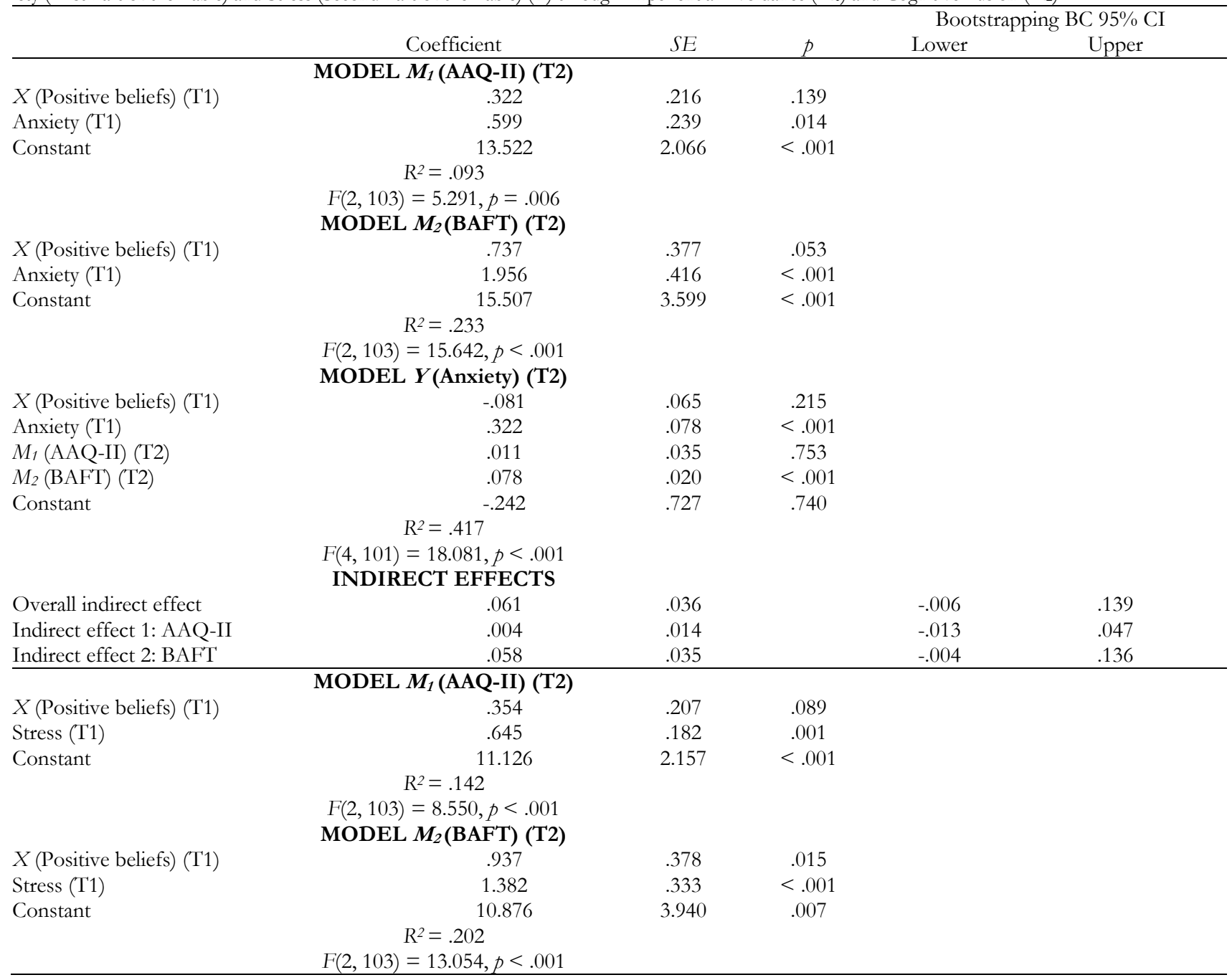




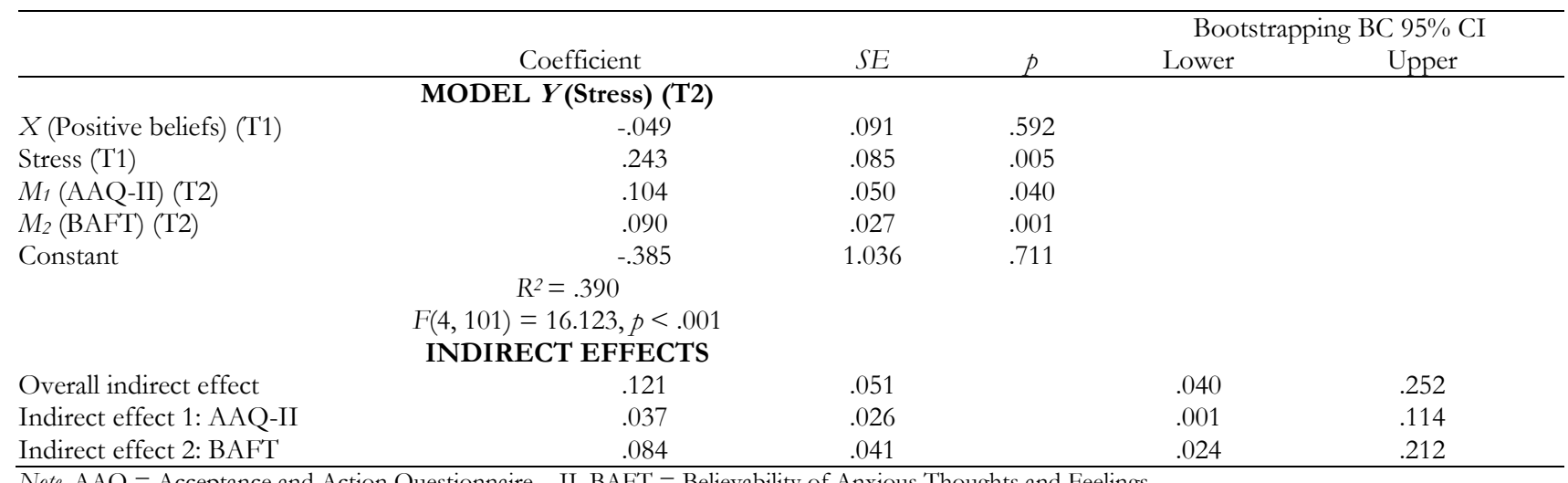

Note. AAQ = Acceptance and Action Questionnaire - II, BAFT = Believability of Anxious Thoughts and Feelings.

\section{Mediation Analyses of the Effect of Negative Meta- cognitive Beliefs on Anxiety and Stress}

Table 3 presents the set of regression analyses conducted to explore the mediating role of experiential avoidance and cognitive fusion in the relationship between negative metacognitive beliefs and anxiety (upper part of the table) and stress (lower part) symptoms. When controlling for anxiety levels at T1, negative metacognitive beliefs $(X)$ at T1 significantly predicted experiential avoidance $\left(M_{1}\right)(T E=.877, S E$ $=.215, p<.001)$ and cognitive fusion at $\mathrm{T} 2\left(M_{2}\right)(\mathrm{TE}=$ 1.336, $\mathrm{SE}=.384, p=.001)$. Only anxiety symptoms at $\mathrm{T} 1$ $(\mathrm{TE}=.309, \mathrm{SE}=.079, p<.001)$ and cognitive fusion at T2 $(T E=.075, S E=.020, p<.001)$ were significant predictors of anxiety symptoms at T2. The model accounted for $40.8 \%$ of the variance. The total indirect effect of negative metacognitive beliefs on anxiety through experiential avoidance and cognitive fusion was significant $(\mathrm{TE}=.106,95 \% \mathrm{BC} \mathrm{CI}$ $\left.[.028, .209], a b_{c s}=.140\right)$, with only the indirect effect through cognitive fusion being statistically significant $(\mathrm{TE}=.100$, $95 \%$ BC CI $\left.[.033, .216], a b_{c s}=.132\right)$.

With respect to stress symptoms, negative metacognitive beliefs $(X)$ at T1 significantly predicted experiential avoidance $\left(M_{1}\right)(T E=.792, S E=.225, p=.001)$ and cognitive fusion at T2 $\left(M_{2}\right)(\mathrm{TE}=1.340, S E=.422, p=.002)$. Only stress symptoms at T1 $(\mathrm{TE}=.230, S E=.090, p=.012)$ and cognitive fusion at T2 $(\mathrm{TE}=.085, S E=.027, p=.002)$ were significant predictors of stress symptoms at T2. Experiential avoidance at T2 marginally predicted stress symptoms at T2 $(T E=.098, S E=.051, p=.058)$. The model accounted for $38.9 \%$ of the variance. The total indirect effect of negative metacognitive beliefs on stress through experiential avoidance and cognitive fusion was significant (TE $=.192,95 \%$ BC CI $\left.[.065, .323], a b_{c s}=.165\right)$, with both specific indirect effects through experiential avoidance (TE $=.077,95 \% \mathrm{BC} C \mathrm{CI}$ $\left.[.006, .203], a b_{c s}=.067\right)$ and cognitive fusion $(\mathrm{TE}=.114$, $95 \%$ BC CI $\left.[.029, .244], a b_{c s}=.098\right)$ being statistically significant.

Table 3. Results from the Regression Analyses Examining the Parallel Multiple Mediator Model of the Effect of Negative Metacognitive Beliefs (X) on Anxiety (First Part of the Table) and Stress (Second Part of the Table) (Y) through Experiential Avoidance $\left(\mathrm{M}_{1}\right)$ and Cognitive Fusion $\left(\mathrm{M}_{2}\right)$.

\begin{tabular}{|c|c|c|c|c|c|}
\hline & & & & Boo & $5 \% \mathrm{CI}$ \\
\hline & Coefficient & SE & $p$ & Lower & Upper \\
\hline & MODEL $M_{1}$ (AAQ-II) (T2) & & & & \\
\hline$X$ (Negative beliefs) (T1) & .877 & .215 & $<.001$ & & \\
\hline Anxiety (T1) & .363 & .232 & .120 & & \\
\hline Constant & 6.394 & 2.566 & .014 & & \\
\hline & $\mathrm{R}^{2}=.203$ & & & & \\
\hline & $F(2,103)=13.102, p<.001$ & & & & \\
\hline & MODEL $M_{2}$ (BAFT) (T2) & & & & \\
\hline$X$ (Negative beliefs) (T1) & 1.336 & .384 & .001 & & \\
\hline Anxiety (T1) & 1.656 & .415 & $<.001$ & & \\
\hline Constant & 6.770 & 4.594 & .144 & & \\
\hline & $R^{2}=.288$ & & & & \\
\hline & $F(2,103)=20.828, p<.001$ & & & & \\
\hline & MODEL $Y$ (Anxiety) (T2) & & & & \\
\hline$X$ (Negative beliefs) (T1) & .015 & .074 & .843 & & \\
\hline Anxiety (T1) & .309 & .079 & $<.001$ & & \\
\hline$M_{1}(\mathrm{AAQ}-\mathrm{II})(\mathrm{T} 2)$ & .007 & .036 & .842 & & \\
\hline$M_{2}(\mathrm{BAFT})(\mathrm{T} 2)$ & .075 & .020 & $<.001$ & & \\
\hline Constant & -.959 & .838 & .255 & & \\
\hline & $\mathrm{R}^{2}=.408$ & & & & \\
\hline & $F(4,101)=17.438, p<.001$ & & & & \\
\hline
\end{tabular}




\begin{tabular}{|c|c|c|c|c|c|}
\hline & & & & Boot & $5 \% \mathrm{CI}$ \\
\hline & Coefficient & SE & $p$ & Lower & Upper \\
\hline & INDIRECT EFFECTS & & & & \\
\hline Overall indirect effect & .106 & .046 & & .028 & .209 \\
\hline Indirect effect 1: AAQ-II & .006 & .031 & & -.051 & .078 \\
\hline Indirect effect 2: BAFT & .100 & .045 & & .033 & .216 \\
\hline & MODEL $M_{1}$ (AAQ-II) (T2) & & & & \\
\hline$X$ (Negative beliefs) (T1) & .792 & .225 & .001 & & \\
\hline Stress (T1) & .375 & .194 & .056 & & \\
\hline Constant & 6.246 & 2.540 & .016 & & \\
\hline & $R^{2}=.212$ & & & & \\
\hline & $F(2,103)=13.881, p<.001$ & & & & \\
\hline & MODEL $M_{2}$ (BAFT) (T2) & & & & \\
\hline X (Negative beliefs) (T1) & 1.340 & .422 & .002 & & \\
\hline Stress (T1) & .959 & .364 & .010 & & \\
\hline Constant & 5.529 & 4.758 & .248 & & \\
\hline & $R^{2}=.230$ & & & & \\
\hline & $F(2,103)=15.374, p<.001$ & & & & \\
\hline & MODEL $Y$ (Stress) (T2) & & & & \\
\hline$X$ (Negative beliefs) (T1) & .049 & 108 & .650 & & \\
\hline Stress (T1) & .230 & .090 & .012 & & \\
\hline$M_{1}(\mathrm{AAQ}-\mathrm{II})(\mathrm{T} 2)$ & .098 & .051 & .058 & & \\
\hline$M_{2}(\mathrm{BAFT})(\mathrm{T} 2)$ & .085 & .027 & .002 & & \\
\hline Constant & -1.132 & 1.168 & .335 & & \\
\hline & $\mathrm{R}^{2}=.389$ & & & & \\
\hline & $F(4,101)=16.090, p<.001$ & & & & \\
\hline & INDIRECT EFFECTS & & & & \\
\hline Overall indirect effect & 192 & .067 & & .065 & .323 \\
\hline Indirect effect 1: AAQ-II & .077 & .048 & & .006 & .203 \\
\hline Indirect effect 2: BAFT & .114 & .053 & & .029 & .244 \\
\hline
\end{tabular}

Note. AAQ = Acceptance and Action Questionnaire - II, BAFT = Believability of Anxious Thoughts and Feelings.

\section{Mediation Analyses of the Effect of Beliefs about the Need to Control on Anxiety and Stress}

Table 4 shows that when controlling for anxiety levels at T1, beliefs about the need to control $(X)$ at T1 significantly predicted experiential avoidance $\left(M_{1}\right)(T E=.689, S E=.212$, $p=.002)$ and cognitive fusion at T2 $\left(M_{2}\right)(\mathrm{TE}=1.345, \mathrm{SE}=$ $.368, p<.001)$. Only anxiety symptoms at $\mathrm{T} 1(\mathrm{TE}=.317$, $S E=.078, p<.001)$ and cognitive fusion at T2 $(T E=.077$, $S E=.021, p<.001)$ were significant predictors of anxiety symptoms at T2. The model accounted for $41 \%$ of the variance. The total indirect effect of beliefs about the need to control on anxiety through experiential avoidance and cognitive fusion was significant (TE $=.112,95 \%$ BC CI [.034, .247], $\left.a b_{c s}=.153\right)$, with only the indirect effect through cognitive fusion being statistically significant $(T E=.104,95 \%$ BC CI [.028, .222], $\left.a b_{c s}=.142\right)$.

Regarding stress symptoms, beliefs about the need to control $(X)$ at T1 significantly predicted experiential avoidance $\left(M_{1}\right)(T E=.617, S E=.213, p=.005)$ and cognitive fusion at T2 $\left(M_{2}\right)(\mathrm{TE}=1.386, S E=.387, p=.001)$. Stress symptoms at $\mathrm{T} 1(\mathrm{TE}=.268, \mathrm{SE}=.086, p=.002)$, cognitive fusion $(T E=.096, S E=.027, p=.001)$ and experiential avoidance $(T E=.111, S E=.050, p=.028)$ at $\mathrm{T} 2$ were significant predictors of stress symptoms at T2. The model accounted for $40 \%$ of the variance. The total indirect effect of beliefs about the need to control on stress through experiential avoidance and cognitive fusion was significant (TE = $.202,95 \%$ BC CI $\left.[.072, .380], a b_{c s}=.187\right)$, with both specific indirect effects through experiential avoidance $(\mathrm{TE}=.068$, $95 \%$ BC CI $\left.[.006, .198], a b_{c s}=.063\right)$ and cognitive fusion (TE $=.133,95 \%$ BC CI $\left.[.048, .266], a b_{c s}=.124\right)$ being statistically significant.

Prediction of Dysfunctional Metacognitive Beliefs, Experiential Avoidance, and Cognitive Fusion at T2

Table 5 shows that the inclusion in Step 3 of experiential avoidance and cognitive fusion, as measured at T1, added incremental explained variance to the prediction of negative metacognitive beliefs, $F(2,98)=7.427, p=.001$, and beliefs about the need to control thoughts, $F(2,98)=8.186, p=$ .001 . Only negative metacognitive beliefs $(\beta=.42)$ and experiential avoidance $(\beta=.22)$ at T1 were significant predictors of negative beliefs at T2, with the model explaining $56 \%$ of the variance. Regarding beliefs about the need to control thoughts, only its levels at T1 $(\beta=.31)$, cognitive fusion $(\beta=$ $.32)$, and negative metacognitive beliefs $(\beta=.19)$ were shown to be significant predictors, with the model explaining $63 \%$ of the variance. The inclusion of experiential avoidance and cognitive fusion did not explain incremental variance in the prediction of positive metacognitive beliefs. 
Table 4. Results from the Regression Analyses Examining the Parallel Multiple Mediator Model of the Effect of Beliefs about Need to Control (X) on Anxiety (First Part of the Table) and Stress (Second Part of the Table) (Y) through Experiential Avoidance $\left(\mathrm{M}_{1}\right)$ and Cognitive Fusion $\left(\mathrm{M}_{2}\right)$.

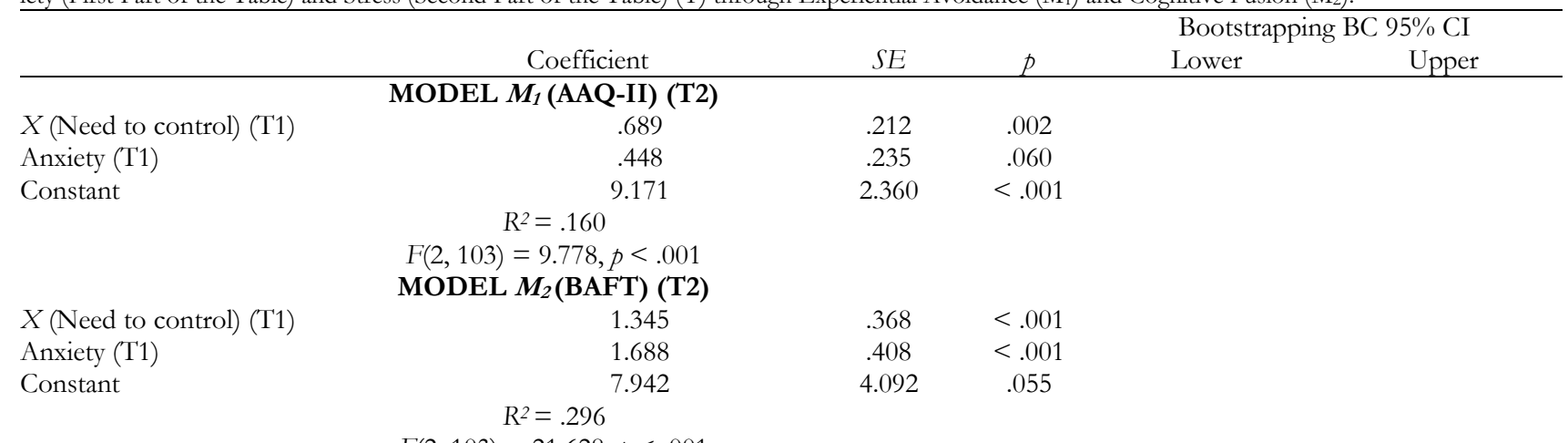

$F(2,103)=21.628, p<.001$

$X($ Need to control) (T1)

Anxiety (T1)

MODEL $Y$ (Anxiety) (T2)

$M_{1}(\mathrm{AAQ}-\mathrm{II})(\mathrm{T} 2)$

$M_{2}(\mathrm{BAFT})(\mathrm{T} 2)$

Constant

$\begin{array}{llc}-.033 & .070 & .635 \\ .317 & .078 & <.001 \\ .011 & .036 & .748 \\ .077 & .021 & <.001 \\ -.574 & .780 & .463\end{array}$

$$
\mathrm{R}^{2}=.410
$$

$F(4,101)=17.517, p<.001$

INDIRECT EFFECTS

Overall indirect effect

Indirect effect 1: AAQ-II

Indirect effect 2: BAFT

$X$ (Need to control) (T1)

Stress (T1)

Constant

\begin{tabular}{lll}
.112 & .055 & \\
.008 & .025 & \\
.104 & .052 & \\
\hline Q-II) (T2) & & \\
.617 & .213 & .005 \\
.493 & .188 & .010 \\
8.350 & 2.334 & .001
\end{tabular}

$F(2,103)=11.646, p<.001$

$X$ (Need to control) (T1)

Stress (T1)

MODEL $M_{2}$ (BAFT) (T2)

Constant

$\begin{array}{lll}1.386 & .387 & .001 \\ 1.054 & .342 & .003 \\ 5.850 & 4.245 & .171\end{array}$

$$
\mathrm{R}^{2}=.248
$$

$F(2,103)=17.003, p<.001$

$X$ (Need to control) (T1)

Stress (T1)

$M_{1}$ (AAQ-II) (T2)

$M_{2}$ (BAFT) (T2)

Constant

\section{MODEL $\boldsymbol{Y}$ (Stress) (T2)}

$\begin{array}{ccc}-.143 & .099 & .152 \\ .268 & .086 & .002 \\ .111 & .050 & .028 \\ .096 & .027 & .001 \\ .321 & 1.078 & .767\end{array}$

$F(4,101)=16.858, p<.001$

Overall indirect effect

INDIRECT EFFECTS

Indirect effect 1: AAQ-II

\section{.202}

.075

.047

.054

.034

$-.033$

.028

.247

.070

.222

Indirect effect 2: BAFT

$133 \quad .054$

.010

Note. AAQ = Acceptance and Action Questionnaire - II, BAFT $=$ Believability of Anxious Thoughts and Feelings. 
Table 5. Hierarchical Regression Analyses of Negative Beliefs, Beliefs about the Need to Control Thoughts, and Positive Beliefs at T2 by Variables at T1.

\begin{tabular}{|c|c|c|c|c|c|c|}
\hline & \multicolumn{2}{|c|}{ NEGATIVE BELIEFS } & \multicolumn{2}{|c|}{ NEED TO CONTROL BELIEFS } & \multicolumn{2}{|c|}{ POSITIVE BELIEFS } \\
\hline & $\beta$ & $\mathrm{R}^{2}$ & $\beta$ & $R^{2}$ & $\beta$ & $\mathrm{R}^{2}$ \\
\hline \multicolumn{7}{|l|}{ STEP 1} \\
\hline Negative beliefs & $.60^{* * *}$ & & $.35^{* * *}$ & & .02 & \\
\hline Positive beliefs & -.03 & .48 & .05 & .55 & $.64 * * *$ & .44 \\
\hline Need to control beliefs & $.17^{*}$ & & $.48 * * *$ & & .06 & \\
\hline \multicolumn{7}{|l|}{ STEP 2} \\
\hline Negative beliefs & $.55^{* * *}$ & & $.30^{* * *}$ & & .05 & \\
\hline Positive beliefs & -.02 & & .07 & & $.64 * * *$ & \\
\hline Need to control beliefs & .15 & .50 & $.46^{* * *}$ & .57 & .08 & .44 \\
\hline Anxiety & -.02 & & -.10 & & -.02 & \\
\hline Stress & .16 & & $.21^{*}$ & & -.07 & \\
\hline \multicolumn{7}{|l|}{ STEP 3} \\
\hline Negative beliefs & $.42 * * *$ & & $.19 *$ & & .01 & \\
\hline Positive beliefs & -.02 & & .07 & & $.64 * * *$ & \\
\hline Need to control beliefs & .01 & & $.31 * * *$ & & .08 & \\
\hline Anxiety & -.08 & .56 & -.17 & .63 & -.02 & .45 \\
\hline Stress & .05 & & .10 & & -.07 & \\
\hline Experiential avoidance & $.22^{*}$ & & .13 & & .15 & \\
\hline Cognitive fusion & .24 & & $.32 * *$ & & -.10 & \\
\hline
\end{tabular}

$* p<.05,{ }^{* *} p<.01, * * * p<.001$.

As shown in Table 6, only experiential avoidance as measured at T1 $(\beta=.78)$ was a significant predictor of scores in experiential avoidance at T2. Experiential avoidance $(\beta=$ .26) and cognitive fusion $(\beta=.35)$ levels at T1 were the only predictors of cognitive fusion at T2. In both cases, dysfunctional metacognitive beliefs did not add incremental explained variance in Step 3.

Table 6. Hierarchical Regression Analyses of Experiential Avoidance and Cognitive Fusion at T2 by Variables at T1.

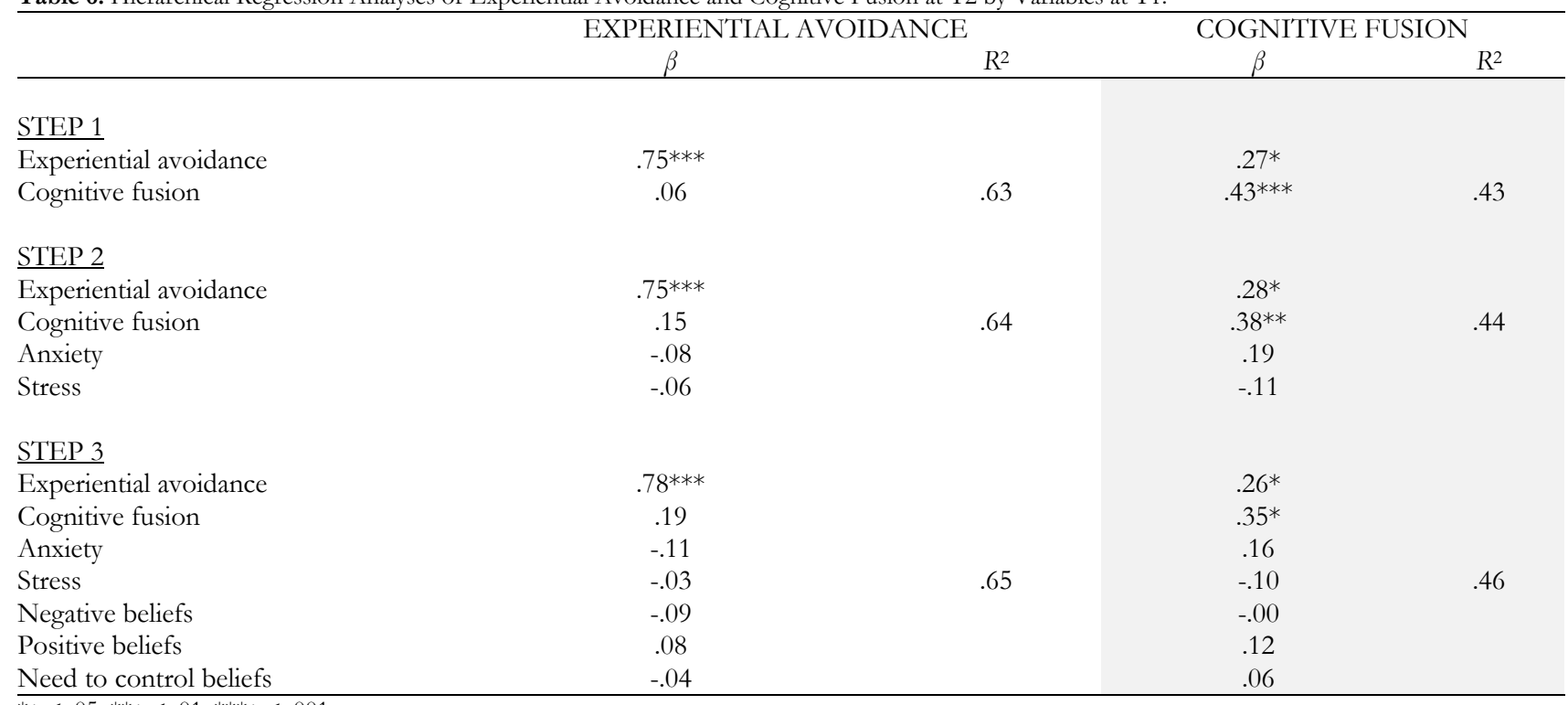

Need to control beliefs

*p<.05, ** $p<.01, * * * p<.001$.

\section{Discussion}

To our best knowledge, the current study is the first empirical comparison of key constructs of the MCT and ACT models of anxiety disorders. Specifically, this study was de- signed to examine two hypotheses. Firstly, according to the S-REF model, we expected that experiential avoidance and cognitive fusion, as similar concepts to the CAS according to our previous theoretical analysis, would longitudinally mediate the relationship between dysfunctional metacognitive beliefs and anxiety and stress symptoms. Secondly, according 
to the ACT model, we expected that experiential avoidance and cognitive fusion at T1 would predict dysfunctional metacognitive beliefs at T2 even when controlling for them and for anxiety and stress symptoms at T1. The results generally supported both hypotheses.

In the mediation analyses, a similar pattern of results was obtained with negative metacognitive beliefs and beliefs about the need to control thoughts. In both cases, cognitive fusion as measured at T2 mediated the effect of those metacognitive beliefs at $\mathrm{T} 1$ on anxiety symptoms at T2. Both cognitive fusion and experiential avoidance acted as mediators of the relationships between these negative metacognitive beliefs and stress symptoms. The results of the mediation analyses conducted with positive metacognitive beliefs were less clear, with cognitive fusion only mediating the relationship between positive beliefs and stress symptoms, but not between positive beliefs and anxiety symptoms (although mediation was significant at $90 \% \mathrm{BC}$ CI). In conclusion, our first hypothesis was supported in almost all cases, with cognitive fusion with anxious thoughts and feelings revealed as a more consistent mediator of the effect of dysfunctional metacognitive beliefs on anxiety and stress symptoms.

The results supported our second hypothesis only in relation to negative metacognitive beliefs. Specifically, experiential avoidance at T1 was a significant predictor of negative metacognitive beliefs at T2 even when controlling for metacognitions and anxiety and stress symptoms at T1. Likewise, cognitive fusion at T1 was shown to be a significant predictor of beliefs about the need to control thoughts. Conversely, metacognitive beliefs at T1 did not predict either experiential avoidance or cognitive fusion at T2 when controlling for their levels at T1. In conclusion, engagement in cognitive fusion and experiential avoidance across time seems to lead to the development of negative metacognitive beliefs but not of positive beliefs.

The results of this study can be seen as supportive of both the ACT and MCT models of anxiety disorders. On the one hand, if we accept that the CAS significantly overlaps with the ACT constructs of cognitive fusion and experiential avoidance, the results are consistent with the S-REF model

\section{References}

Antony, M. M., Bieling, P. J., Cox, B. J., Enns, M. W., \& Swinson, R. P. (1998). Psychometric properties of the 42-item and 21-item versions of the Depression Anxiety Stress Scales (DASS) in clinical groups and a community sample. Psychological Assessment, 10, 176-181.

Ato, M., \& Vallejo, G. (2007). Diseños experimentales en Psicología [Experimental designs in Psychology]. Madrid: Pirámide.

Ato, M., \& Vallejo, G. (2011). Los efectos de terceras variables en la investigación psicológica [The effect of third variables in psychological research]. Anales de Psicologia, 27, 550-561.

Bond, F. W., Hayes, S. C., Baer, R. A., Carpenter, K. M., Guenole, N., Orcutt, H. K., ... Zettle, R. D. (2011). Preliminary psychometric properties of the Acceptance and Action Questionnaire - II: A revised measure of psychological inflexibility and experiential avoidance. Behavior Therapy, 42, 676-688. insofar that the CAS, as measured by the ACT processes, mediated the effect of dysfunctional metacognitive beliefs on anxiety and stress symptoms. On the other hand, dysfunctional metacognitive beliefs can be seen in the ACT context as verbal rules that prompt cognitive fusion with anxious thoughts and feelings and the use of experiential avoidance strategies (e.g., rumination, worry, thought suppression, etc.) to deal with them. For instance, positive metacognitive beliefs prompt the use of worry, rumination, and counterproductive coping behaviors such as suppression, threat monitoring, and avoidance to deal with anxiety. Likewise, negative metacognitive beliefs prevent the person from interrupting worry and rumination, and promote further engagement in experiential avoidance because anxiety experiences are viewed as dangerous. However, according to our second hypothesis, engaging in cognitive fusion and experiential avoidance predicts the development of negative metacognitive beliefs, which then further support the ACT processes.

Some limitations of the current study are worth mentioning. Firstly, as all data were obtained using self-report measures, relationships among variables might be artificially inflated. Secondly, as the sample was made up of nonclinical participants, generalizability of the current findings may be limited. Thirdly, only 106 participants completed the study out of the 289 who responded to the survey at T1. However, no differences in the scores on the psychological constructs of interest were found between completers versus noncompleters. Lastly, the longitudinal design used in this study does not allow for attributions of causality because no independent variable was manipulated in this study. Nonetheless, longitudinal studies such as this one provide a way to explore the interrelations of key concepts of psychological models of anxiety disorders.

In conclusion, this is the first study that longitudinally compared key constructs of MCT (dysfunctional metacognitive beliefs) and ACT (experiential avoidance and cognitive fusion) in the prediction of anxiety and stress symptoms. The results were compatible with both models and warrant the examination of further similarities between them.

Borkovec, T. D. (1994). The nature, functions, and origins of worry. In G. Davey \& F. Tallis (Eds.), Worrying: Perspective on theory, assessment, and treatment (pp. 5-33). Sussex, UK: John Wiley \& Sons.

Daza, P., Novy, D. M., Stanley, M., \& Averill, P. (2002). The Depression Anxiety Stress Scale-21: Spanish translation and validation with a Hispanic sample. Journal of Psychopathology and Behavioral Assessment, 24, 195205.

Giorgio, J. M., Sanflippo, J., Kleiman, E., Reilly, D., Bender, R. E., Wagner, C. A., ... Alloy, L. (2010). An experiential avoidance conceptualization of depressive rumination: Three tests of the model. Behaviour Research and Therapy, 48 ,

Hayes, A. F. (2013). Introduction to mediation, moderation, and conditional proces analysis. A regression-based approach. New York, NY: Guilford Press.

Hayes, S. C., Strosahl, K. D., \& Wilson, K. G. (1999). Acceptance and commitment therapy. An experiential approach to behavior change. New York, NY: Guilford Press. 
Hayes, S. C., Wilson, K. G., Gifford, E. V., Follette, V. M., \& Strosahl, K. D. (1996). Experiential avoidance and behavioral disorders: A functional dimensional approach to diagnosis and treatment. Journal of Consulting and Clinical Psychology, 64, 1152-1168.

Herzberg, K. N., Sheppard, S. C., Forsyth, J. P., Credé, M., Earleywine, M., \& Eifert, G. H. (2012). The Believability of Anxious Feelings and Thoughts Questionnaire (BAFT): A psychometric evaluation of cognitive fusion in a nonclinical and highly anxious community sample. Psychological Assessment, 24, 877-891.

Kenny, D. A. (2014, April 9). Mediation. Retrieved from http://davidakenny.net $/ \mathrm{cm} /$ mediate.htm

Odriozola-González, P. (2011). El papel del pensamiento mágico en las alucinaciones y el trastorno obsesivo compulsivo. Comparación entre grupos clínicos y no clínicos. [The role of magical thinking in hallucinations and obsessive-compulsive disorder. Comparison between clinical and nonclinical groups] (Unpublished doctoral dissertation). Universidad de Oviedo, Oviedo.

Preacher, K. J., \& Kelley, K. (2011). Effect size measures for mediation models: Quantitative strategies for communicating indirect effects. Psychological Methods, 16, 93-115.

Roemer, L., \& Orsillo, S. M. (2002). Expanding our conceptualization of and treatment for generalized anxiety disorder: Integrating mindful- ness/acceptance-based approaches with existing cognitive-behavioral models. Clinical Psychology: Science and Practice, 9, 54-68.

Ruiz, F. J., Langer, A. I., Luciano, C., Cangas, A. J., \& Beltrán, I. (2013). Measuring experiential avoidance and psychological inflexibility: The Spanish translation of the Acceptance and Action Questionnaire. Psicothema, 25, 123-129.

Ruiz, F. J., Odriozola-González, P., \& Suárez-Falcón, J. C. (2014). The Spanish version of the Believability of Anxious Feelings and Thoughts. Psicothema, 26, 308-313.

Ruiz, F. J., Suárez-Falcón, J. C., Cárdenas-Sierra, S., Durán, Y., Guerrero, K., \& Riaño-Hernández, D. (2016). Psychometric properties of the Acceptance and Action Questionnaire - II in Colombia. The Psychological Record, 66, 429-437.

Wells, A. (2000). Emotional disorders and metacognition: Innovative cognitive therapy. Chichester, UK: Wiley.

Wells, A. (2009). Metacognitive therapy for anxiety and depression. New York, NY: Guilford Press.

Wells, A., \& Cartwright-Hatton, S. (2004). A short form of the Metacognitions Questionnaire: Properties of the MCQ-30. Behavior Research and Therapy, 42, 385-396.

Wells, A., \& Matthews, G. (1994). Attention and emotion: A clinical perspective. Hove, UK: Erlbaum.

(Article received: 14-05-2015; revised: 10-07-2015; accepted: 11-08-2015) 